\title{
Good Language Learner: A Case Study of Writing Strategies
}

\author{
Parviz Maftoon \\ Department of English Language, Science and Research Branch, Islamic Azad University, Tehran, Iran \\ Email: pmaftoon@srbiau.ac.ir \\ Seyyed Hassan Seyyedrezaei \\ Department of English Language, Aliabad Katoul Branch, Islamic Azad University, Aliabad Katoul, Iran \\ Email: srezaei.sh@gmail.com
}

\begin{abstract}
The search for the common features of "good language learners" has obsessed scholars such as Naiman et al. (1978), Rubin (1975), and Stevick (1989). Regarding those with good writing skill in particular, some (Angelova, 1999; Beare, 2000; Victori, 1995) list some features such as language proficiency, L1 writing competence, use of cohesive devices, meta cognitive knowledge about the writing task. The purpose of this study was to find the cognitive and metacognitive strategies of a successful learner in writing skill (considering those suggested by Arndt, 1987; Wenden, 1991). Tina, a 27 year old language learner with a BS degree in architecture, was found the most suitable case based on the teacher's observation of her good writing and the analysis of Oxford's (1990) strategy inventory for language learning (SILL) administered. The data collected from the observation of her writing, the think-aloud protocol and the interview showed that Tina made use of most of the cognitive and metacognitive strategies listed but there was no evidence of $\mathrm{L} 1$ reliance in her L2 writing. The data also revealed that she was highly good at using prefabricated phrases and sentences in her writing.
\end{abstract}

Index Terms - good language learner, cognitive strategies, metacognitive strategies, L1 reliance, pre-fabricated sentences

\section{INTRODUCTION}

One of the main questions in the second language acquisition area posed frequently is why some people are better at learning languages compared to others. Early studies on good language learners (GLLs), such as Naiman et al. (1978), Rubin (1975), and Stevick (1989) show that GLLs tend to share some strategies for learning and thus indicate that research on their strategies might help facilitate our understanding of the learning process of a second/foreign language. Learning strategies are the conscious thoughts and actions that learners take in order to achieve a learning goal. Strategic learners have metacognitive knowledge about their own thinking and learning approaches, a good understanding of what a task entails, and the ability to orchestrate the strategies that best meet both the task demands and their own learning strengths (Chamot, 2004).Since then, a large number of empirical studieshave been conducted to ascertain the strategies favored by GLLs and the factors affecting their use.

A wide variety of factors related to LLS have been investigated by researchers such as Oxford (1990), O'Malley and Chamot (1990), and Cohen (1998), along with many others. Among such factors, the language, level of proficiency, gender and motivation were definitely shown to be strongly related to learners' strategy choice. Language teachers consider the learners' strategies and motivation as integral elements in the design and implementation of effective language instruction. According to Cohen (2005), LLS are important in language learning and teaching for two major reasons: (a) researchers can identify the metacognitive, cognitive, social and affective processes involved in language learning by investigating the strategy use of second language learners, (b) less successful language learners can be assisted to be better language learners through effective strategy instruction. The second reason is more important for classroom pedagogy and O'Malley and Chamot (1990) claim that language learners can improve their language performance by using instructed learning strategies.To find the features of good language learners, Carroll (1967) investigates the learning biographies of persons who had beensuccessful in learning more than one language, and Stern (1975) and Rubin (1975) all speculate about distinctive learningstrategies of good language learners.

There have been a number of attempts, Naiman et al. (1978), Stern (1983), Lightbown and Spada (1993), and Ellis (1994), Rubin (1975), for instance, to identify the qualities of the good language learners. Naiman et al. (1978) propose "Good language learner" model. The model consists of five classes of variables in language learning. The teaching, the learner and the context are three independent causative variables. The learning and the outcome are the caused variables. The independent variables, i.e. teaching, the learner and the context are then subdivided into various aspects. Naiman et al. (1978) identify five major strategies for language learning:

1. active task approach (Good language learners actively involve themselves in the language learning task). 
2. realization of language as a system (Good language learners develop or exploit an awareness of language as a system).

3. realization of language as a means of communication and interaction.

4. management of affective demands (good language learners realize initially or with time that they must cope with the affective demands made upon them by language learning and succeed in doing so).

5. monitoring of performance in the target language.

The most frequently used techniques (Naiman et al., 1978) by good language learners include having contact with native speakers; listening to radio, T.V., records, movies, commercials etc.; reading anything: magazines, newspapers, professional articles, comics, etc.; repeating aloud after teacher and/or native speaker; making up bilingual vocabulary charts and memorizing them; following the rules as given in grammar books or text books and having pen-pals.

Active planning strategy, academic learning strategy, social learning strategy and affective learning strategy, according to Stern (1983), are four basic strategies which good language learners use. Stern (1983) goes on to say that good language learners are prepared to study and practice. As they are aware that language is a formal system with rules and regular relationships between language forms and meaning, they will pay more attention to these features. They also develop the second language as a consciously perceived system which they constantly revise until the learning process is completed. In addition, they analyze the language and use appropriate techniques of practice and memorization.

To Lightbown and Spada (1993), the good language learner:

- is a willing and accurate guesser.

- tries to get a message across even if specific language knowledge is lacking.

- is willing to make mistakes.

- constantly looks for patterns in the language.

- practices as often as possible.

- analyzes his/her own speech and the speech of others.

- attends to whether his or her performance meets the standards he or she has learned.

- enjoys grammar exercises.

- begins learning in childhood.

- has an above-average IQ.

- has good academic skills.

- has a good self-image and lots of confidence.

Successful language learning, according to Ellis (1994), is characterized by a concern for language form; a concern for communicative/functional practice; an active approach to learning tasks; an awareness of the learning process and the ability to use strategies flexibly in the light of different task requirements.

The factors influencing good writing has been mentioned in different studies as well. For instance, Angelova (1999) lists some features such as language proficiency, L1 writing competence, use of cohesive devices, metacognitive knowledge about the writing task, writing strategies andwriters' personal characteristics. Among these factors, writing strategies seem particularly remarkable because many researchers (Beare, 2000; Victori, 1995) claim that it is the writing strategies that primarily separate successful from less successful writers. Furthermore, according to Hsiao and Oxford (2002), strategies can "pave the way toward greater proficiency, learner autonomy, and self-regulation" (p. 372). Therefore, it is necessary to explore explicit classification of ESL writing strategies from theoretic stance so that ESL learners can easily access to and acquire to facilitate their writing.

Arndt's (1987) adopts eight categories to code the strategies the students used in their writing as the following table shows.

TABLE 1.

ARNDT'S CATEGORIES OF ESL WRITING STRATEGIES

\begin{tabular}{|l|l|}
\hline Category of strategies & Definition \\
\hline Planning & Finding a focus, deciding what to write about \\
Global planning & Deciding how to organize the text as a whole \\
Rehearsing & Trying out ideas and the language in which to express them \\
Repeating & Of key words and phrases - an activity which often seemed to \\
Re-reading & provideimpetus to continue composing; \\
Questioning & Of what had already been written down \\
Revising & As a means of classifying ideas, or evaluating what had been written \\
Editing & Making changes to the written text in order to clarify meaning \\
& Making changes to the written text in order to correct the syntax or \\
& spelling \\
\hline
\end{tabular}

Wenden (1991) studies how the students used metacognitive strategies in their writing and discusses what task knowledge they searched for before and while writing. The cognitive and meta cognitive strategies she mentions are summarized in Table 2. 
TABLE 2.

Cognitive AND METACOGNITIVE STRATEGIES IN WRITING PROPOSED By WENDEN (1991)

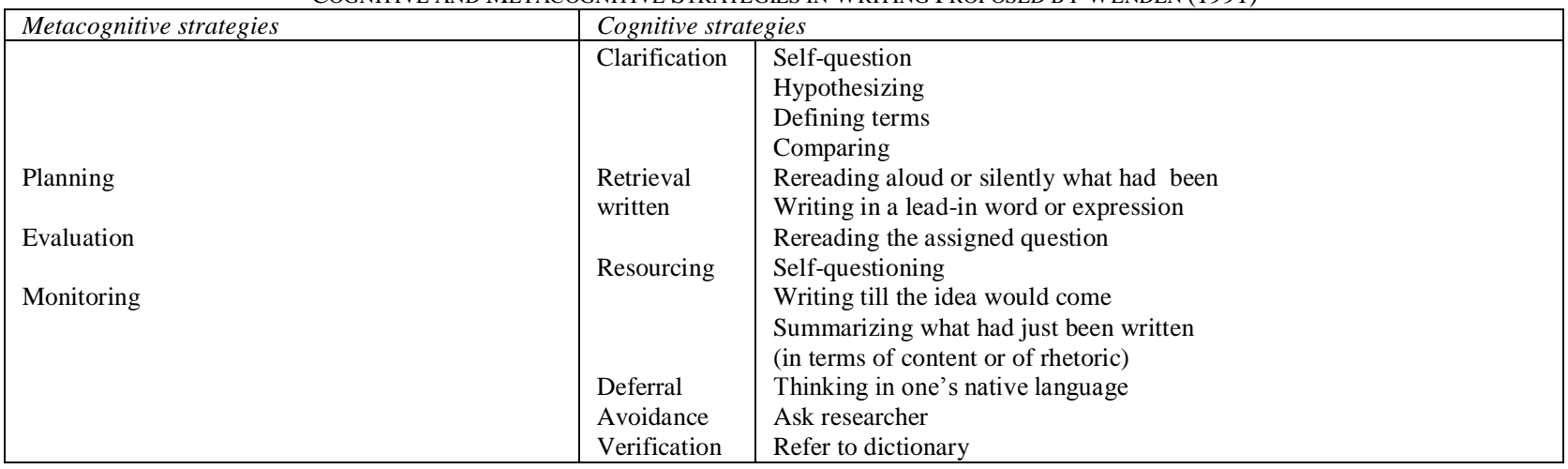

Wenden (1991) goes on to explain that metacognitive strategies are mental operations or procedures that learners use toregulate their learning. They are directly responsible for the execution of a writing task and include three main kinds: planning, evaluating and monitoring. Cognitive strategies are mental operations or steps used by learners to learn new information and apply it to specific learning tasks. They are used to deal with the obstaclesencountered along the way. They are auxiliary strategies that aid in the implementation of the metacognitivestrategies. Unlike the metacognitive strategies, the function of cognitive strategies is narrower in scope.

Victori (1995) has identified seven types of writing strategies based on the interviews and think-aloud protocol analysis. According to Victori (1995), planning strategies are strategies by which the writer plans and talks out what ideas will come next, and explicitly states his or her objectives for organization and procedures. Monitoringstrategies are strategies the writers use when checking and verifying their process in the composing process andwhen identifying oncoming problems. Evaluating strategies are strategies undertaken when reconsidering the written text, previous goals, planned thoughts, as well as changes undertaken to the text. Resourcing strategiesare strategies using available external reference sources of information about the target language, such asconsulting the dictionary to look up or confirm doubts (lexicon, grammatical, semantic or spelling doubts), or to look for alternatives (synonyms). Repeating strategies are strategies repeating chunks of language in the course of composing, either when reviewing the text or when transcribing new ideas. Reduction strategies are strategies to do away with a problem, either by removing it from the text, giving up any attempts to solve it, or paraphrasing with the aim of avoiding a problem. Use of L1 strategies are strategies using the mother tongue with different purposes: to generate new ideas, to evaluate and make sense of the ideas written in the L2 or to transcribe the right idea and word in L1.

\section{The CASE STUdy}

In order to come up with a suitable case for the study, the researcher administered Oxford's (1990) strategy inventory for language learning (SILL) among 31 of his students in writing classes in Giti language institute (Gorgan, Iran) who attended IELTS preparation courses. After analyzing all the students` responses to the strategy inventory and also considering the writing samples by the students, Tina, a 27 year old language learner with a BS degree in architecture, was found conspicuously one of the best students with highly noticeable writing skill.

Concerning the characteristics of good language learners cited above, the following research questions were raised to see:

1) What are the cognitive strategies employed by Tina as a case of good language learner with highly good writing skill in writing?

2) What are the metacognitive strategies employed by Tina as a case of good language learner with highly good writing skill in writing?

3) Does Tina`s reliance on her L1 writing influence her L2 writing?

\section{A. Instruments}

1. Oxford's (1990) strategy inventory for language learning (SILL). This questionnaire includes 50 items. It was used to find the good language learners.

2. The think-aloud protocol: to examine Tina's L1 reliance in L2 writing.

3. An interview: to ask her to discuss her learning backgrounds, writing experiences in L1 and L2, writing strategies, and handling of writing assignments.

\section{B. Procedure}

In the first place, Oxford's (1990) strategy inventory for language learning (SILL) was administered among 31 of his students in IELTS writing courses in Giti language institute (Gorgan, Iran). In the IELTS writing course that lasted about three months, the researcher who was the teacher himself asked the language learners to send the writing sample to different topics of the two tasks via email. The learners` writing samples showed Tina, a 27 year-old language learner 
with a BS degree in architecture, markedly best in applying very good writing strategies. Analyzing the questionnaires` responses also supported the abovementioned selection.

After that, the think-aloud protocol was administered. She was given a topic and then asked to write a text for an hour. She was asked to bring her own resources such as dictionaries, reference books, and a computer that she usually used while writing. While writing, she was asked to think aloud any thoughts running through their heads. Finally, an interview was conducted to ask her to describe the strategies she used in writing. The interview was audio-taped. In sum, the data were collected from multiple sources: the questionnaire, observations, the think-aloud protocol and the interview.

\section{Data Analysis}

The teacher`s observation of Tina`s writing samples along with her responses to Oxford`s (1990) inventory showed that she was a good language learner with noticeable writing skills. The think-aloud protocol revealed that she made use of most of cognitive and metacognitive strategies in writing (suggested by Wenden, 1991) as she thought aloud saying:

Metacognitive strategies:

\section{- Planning:}

"I should now think of the idea and how to write it."

Tina focused on the topic for a while to decide what to write about. During planning, she made an outline of the main points on a piece of paper. Thinking for a while, she thought she added other parts and deleted some others. During planning, she also made decisions about the kinds of examples, reasons and other devices to support her idea. Then, she started to write. While writing, she also referred to the early outline she designed and thought whether what she wrote was compatible with what she designed previously. She also made some changes in the ideas and the kinds of organizations while writing. All in all, she had pre-writing as well as while writing planning as explained above.

\section{- Evaluation and monitoring:}

"Now I should check the grammar, punctuation ...spelling and the coherence."

Tina also monitored and evaluated her writing both during and after the writing. She checked whether what she wrote was compatible with the main idea and whether the paragraphs had been developed well. Using monitoring strategies, she also identified some problems creeping in the writing process. For instance, she could not support the idea with the reasons so she planned to do it through examples. When her writing finished, she used some evaluative strategies while reconsidering the written text, previous goals, planned thoughts, as well as changes undertaken to the text. For example, she crossed out some parts because they were not based on the previous goals. She also corrected some grammatical, punctuation and lexical errors.

Tina`s use of some of cognitive strategies was also conspicuous in her think-aloud protocol. They are discussed as follows:

- Retrieval:

She reread aloud or silently what had been written. She also reread the assigned question. During writing, she selfquestioned. Besides, she summarized what had just been written (in terms of content or of rhetoric).

- Resourcing:

While writing, Tina referred to different types of dictionaries: monolingual, bilingual, and collocation. She looked up words in a monolingual dictionary for different purposes: checking spelling, parts of speech and correct usage. She made use of a bilingual (Farsi to English) dictionary to find the English equivalents for the words she did not know. Furthermore, she consulted sometimes a dictionary of collocations for the correct collocations.

- Avoidance:

"I am not sure about it...I should use another structure."

Avoidance strategy was another good strategy applied by Tina in writing. The Think-aloud protocol revealed that whenever she was not sure about a particular structure, she avoided using it. Instead, she used a structure she was sure to compose her ideas.

- Verification:

"Ok. It shows what I mean."

Tina also verified what she wrote while reviewing. She verified all she composed in line with the main idea and the coherence.

Interview data, as Tina described the strategies she used while composing, not only supported the finding by the think-aloud protocol but also revealed other cognitive and metacognitive strategies not identified in the think-aloud protocol as she said,

- Planning:

"I have a plan before writing. I think in advance what I should write so I design an outline first."

- Evaluation and monitoring:

"I check grammar, cohesion ties....."

Regarding cognitive strategies, in addition to those revealed by the think-aloud protocol (retrieval, resourcing, avoidance and verification), the interview showed Tina employed the following strategies as well:

Clarification: 
The interview revealed that Tina made use of the following strategies to clarify her ideas and communicate them clearly.

- Hypothesizing:

"I try to make an idea and follow to make it clear".

In the prewriting planning, Tina made a thesis statement about the topic by hypothesizing and during writing she tried to prove it using different devices available to her.

- Defining terms:

"Sometimes, I define the terms that I think hard and better to be defined for understanding".

In order to communicate her ideas clearly and smoothly, she also stated that she defined some words that she predicted the reader(s) would find sophisticated or ambiguous. She said she defined such terms to avoid ambiguity and help clear understanding.

Concerning the last question "Does Tina`s reliance on her L1 writing influence her L2 writing?", neither the thinkaloud protocol nor the interview showed Tina`s L1 reliance in L2 writing. She herself said,

"I am not used to writing in Farsi and I think the process of writing in Farsi and English is different".

So it can be concluded that she was little affected by writing in Farsi as she did not write in Farsi and the two languages are of two different frameworks in writing.

The observation of her writing showed that she was very good at employing the prefabricated sentences and phrases learned from reading in her writing as she herself said,

"Whenever I read, I try to record the prefabricated as well as useful phrases to use in my writing."

It is, in fact, one of the characteristics of a good writer who uses reading as an input for the writing as an output. Her last statement revealed that she used reading as a framework and the source for learning phrases and prefabricated statements for her writing.

\section{DisCUSSION AND CONCLUSION}

In order to find the features common in good language learners and to help the poor language learners applying those strategies and features, studies such as Naiman et al. (1978), Rubin (1975), and Stevick (1989) list some strategies and characteristics. Regarding those with good writing skill, some (Angelova, 1999; Beare, 2000; Victori, 1995) list some features such as language proficiency, L1 writing competence, use of cohesive devices, meta cognitive knowledge about the writing task as the common characteristics in good language learners in writing skill.

The purpose of this study was two-fold: first, it tries to identify the cognitive and metacognitive strategies of a successful learner in writing skill based on the list provided by (Arndt, 1987; Wenden, 1991). It was also aimed at finding whether Tina`s reliance on her L1 writing influenced her L2 writing. The data collected from the think-aloud protocol and the interview showed that Tina made use of most of the cognitive and meta cognitive strategies listed by Wenden (1991) but she did not rely on her L1 writing for L2 writing. She was found to be very good at employing the prefabricated sentences and phrases learned from reading in her writing.

It can be concluded that in addition to language proficiency, the application of cognitive and metacognitive strategies and activation of prefabricated sentences and phrases characterize Tina`s good writing. As the purpose of writing is to communicate one`s ideas clearly and logically, writers should implement both cognitive strategies (clarification, retrieval, resourcing and verification) and metacognitive strategies (planning, evaluation, monitoring). It also accentuates the importance of teaching these strategies in writing courses to help the students to write more clearly and effectively. In Oxford`s (2003) words, L2 learning strategies are specific behaviors or thought processes that students use to enhance their own L2 learning, so it is incumbent up on the teachers to acquaint the students with these strategies.

\section{REFERENCES}

[1] Angelova, M. (1999). An exploratory study of factors affecting the process and product of writing in English as a foreign language. Unpublished Ph.D. dissertation, State University of New York, Buffalo.

[2] Arndt, V. (1987). Six writers in search of texts: A protocol-based study of L1 and L2 writing. ELT Journal, 41, $257-267$.

[3] Beare, S. (2000). Differences in content generating and planning processes of adult L1 and L2 proficient writers. Unpublished $\mathrm{PhD}$ dissertation, University of Ottawa.

[4] Carroll, J. B. (1967). Research problems concerning the teaching of foreign or second languages to younger children. In H. H. Stern (Ed.), Foreign languages in primary education (pp. 94-109). London: Oxford University Press.

[5] Chamot, A. U. (2004). Issues in language learning strategy research and teaching. Electronic Journal of Foreign Language Teaching, 1(1), 14-26.

[6] Cohen, A. D. (1998). Strategies in learning and using a second language. New York: Addison Wesley Longman Limited.

[7] Cohen, A.D. (2005). Language learning strategy instruction: current issues and research. Annual Review of Applied Linguistics, $25,112-130$.

[8] Ellis, R. (1994). The study of second language acquisition. Oxford: Oxford University Press.

[9] Hsiao, T. Y., \& Oxford, R. L. (2002). Comparing theories of language learning strategies: A confirmatory factor analysis. The Modern Language Journal, 86(3), 368-383.

[10] Lightbown, P., \& Spada, N. (1993). How languages are learned. Oxford: Oxford University Press. 
[11] Naiman, N., Froanhlich, M., Stern, H.H., \& Toedesco, A. (1978).The good language learner. Toronto: OntarioInstitute for Studies in Education (OISE).

[12] O’Malley, J. M., \& Chamot, A. U. (1990). Learning strategies in second language acquisition. Cambridge: Cambridge University Press.

[13] Oxford, R. L. (1990). Language learning strategies: What every teacher should know. Boston: Heinle \& Heinle.

[14] Oxford, R. (2003). Language learning styles and strategies: An overview. GALA, 1-25.

[15] Rubin, J. (1975). What the "good language learner" can teach us. TESOL Quarterly, 9, 41-51.

[16] Stern, H. H. (1975). What can we learn from the good language learner? The Canadian Modern Language Review, 31, 304-318.

[17] Stevick, E. (1989). Success with foreign languages: Seven who achieved it and what worked for them. New York: Prentice Hall International.

[18] Victori, M. (1995). EFL writing knowledge and strategies: An interactive study. Unpublished PhD dissertation, Universitat Autonoma de Barcelona (Spain), Barcelona.

[19] Wenden, A. L. (1991). Metacognitive strategies in L2 Writing: A case for task knowledge. In J. E. Alatis (Ed.), Georgetown university round table on languages and linguistics 1991 (pp. 302-322). Washington, D.C.: Georgetown University Press.

Parviz Maftoon is an associate professor at Islamic Azad University of Tehran, Science and Research Branch. He has been teaching M.A. and Ph.D. courses at different Iranian Universities for the past thirty years. He has published a number of articles and textbooks in TEFL. His fields of interest include SLA, curriculum development, second language writing, teacher training, and ESP.

Seyyed Hassan Seyyedrezaei is a Ph.D. student in ELT at Islamic Azad University, Tehran, Science and Research Branch. He is a faculty member at Islamic Azad University, Aliabad Katoul Branch. He is the author of a number of articles and textbooks in TEFL and presented dozens of articles in different conferences throughout the world. 